\title{
REPRESENTAÇÃO POLÍTICA EM 3-D Elementos para uma teoria ampliada da representação política*
}

\section{Luis Felipe Miguel}

Nos últimos trinta anos, a democracia eleitoral viveu uma fantástica expansão no mundo - aquilo que Samuel Huntington rotulou como "terceira onda" democratizadora, com o colapso de dezenas de regimes autoritários e totalitários. No entanto, um outro processo, contraditório, ocorreu de forma simultânea: a deterioração da adesão popular às

* Uma versão anterior deste artigo foi apresentada no Seminário Internacional de Ciência Política, realizado em Porto Alegre, de 3 a 5 de outubro de 2001. O texto já estava pronto quando me chamaram a atenção para um artigo de Wanderley Guilherme dos Santos, intitulado "Poliarquia em 3-D" (Dados, 41 (2): $207-$ 281, Rio de Janeiro, 1998). Registro aqui a coincidência, que se limita ao título. E quero agradeçer os COmentários ao texto, de Regina Dalcastagnè e dos pareceristas anônimos da $R B C S$, além das discussões com os alunos do curso "Representação Política", na pós-graduação em Ciência Política da UnB.

Artigo recebido em agosto/2001.

Aprovado em maio/2002. instituições representativas. É possível detectar uma crise do sentimento de estar representado, que compromete os laços que idealmente deveriam ligar os eleitores a parlamentares, candidatos, partidos e, de forma mais genérica, aos poderes constitucionais. O fenômeno ocorre por toda a parte, de maneira menos ou mais acentuada, atingindo novas e velhas democracias eleitorais.

Neste artigo, sustento que a recuperação dos mecanismos representativos depende de uma maior compreensão do sentido da própria representação. Na medida em que os grupos subalternos obtêm êxito na busca da inclusão política ou, ao menos, demonstram uma consciência mais aguda do problema, as tensões presentes no campo político se ampliam. Um modelo representativo inclusivo precisa contemplar com mais cuidado as questões ligadas à formação da agenda, ao acesso aos meios de comunicação de massa e às esferas de produção de interesses coletivos. 
Uma afirmação tão genérica - crise disseminada da representação política, em novas e velhas democracias - é de difícil comprovação, mas creio que ela se sustenta sobre três conjuntos de evidências, relativas ao declínio do comparecimento eleitoral, à ampliação da desconfiança em relação às instituições, medida por surveys, e ao esvaziamento dos partidos políticos. Os dados mais objetivos dizem respeito ao primeiro ponto: o aumento na quantidade das abstenções, comparativamente às duas ou três primeiras décadas do pós-guerras. Nem sempre é simples interpretar os números, já que em muitos países ocorreu, no período, a ampliação da franquia eleitoral a novas categorias da população (mulheres, na Suíça; negros, no Sul dos Estados Unidos; analfabetos e jovens entre 16 e 18 anos, no Brasil, para citar apenas três exemplos), bem como a transição de sistemas de voto obrigatório para voto facultativo. Porém, é mais ou menos generalizada a tendência à redução no comparecimento às urnas.

O caso dos Estados Unidos é emblemático. O comparecimento às eleições presidenciais oscilou entre $58,3 \%$ e $63,1 \%$ da população em idade de votar entre 1952 e 1968; a partir daí, inicia uma curva francamente descendente, alcançando o mínimo de 47,2\% em 1996 (e 51,2\% nas últimas eleições, em 2000). Nas votações para o Congresso, o índice é sempre sensivelmente menor. ${ }^{1}$ Diante disso, os cerca de 70\% das eleições gerais holandesas de 1998 parecem invejáveis, mas se trata do menor comparecimento do pós-guerras, num país em que, até 1986, a participação eleitoral ficou abaixo dos 80\% em um único pleito, chegando, por vezes, a superar os 90\%.

Tendência similar é observada em outras democracias eleitorais consolidadas, como Reino Unido, França, Itália, Suíça, Áustria, Canadá e, em menor medida, Japão, Alemanha, Finlândia, Bélgica e Austrália (mas não Suécia, Noruega, e Dinamarca). ${ }^{2}$ Em países democratizados há menos tempo, o padrão predominante é menos claro. O comparecimento eleitoral caiu de forma drástica em Portugal, após o salazarismo, e em alguns países ex-comunistas, como Bulgária, Hungria e Albânia; a tendência de queda é perceptível também na Rússia e na Romênia, mas não na Grécia (onde o voto é obrigatório), na Espanha, na Polônia ou na Croácia.

Nos países latino-americanos, a observação do fenômeno é menos fácil, devido à adoção generalizada do voto obrigatório. Mas é possível fazer uma aproximação por meio do conceito de "alheamento decisório eleitoral", que engloba todas as formas pelas quais os cidadãos e cidadãs se recusam a optar por um partido ou candidato, por meio da abstenção, do não-alistamento eleitoral, do voto nulo ou do voto em branco (Ramos, 2001). No Brasil, nas eleições gerais de 1998, apenas $78,5 \%$ dos eleitores registrados compareceram para votar, o menor índice após a redemocratização; dos votos contados para presidente, 18,7\% foram em branco ou nulos. Somem-se a isso os cerca de $10 \%$ da população em idade de votar que não se alistaram (já que o registro é opcional para analfabetos e jovens entre 16 e 18 anos). No final das contas, mais de $40 \%$ dos brasileiros e brasileiras em idade de votar desprezaram o direito de escolher o presidente da República.

Segundo uma interpretação difundida por Seymour Lipset em seu influente Political man (1963 [1960]), os altos índices de abstenção não significam necessariamente uma demonstração de insatisfação com o sistema político. Ao contrário, revelariam o contentamento disseminado com as instituições, que estariam funcionando tão bem que nem seria necessário participar. Elogios similares às virtudes da apatia são encontrados, na mesma época, no livro de Almond e Verba (1963) sobre a cultura política e, um pouco mais tarde, após os eventos de 1968, no relatório à Comissão Trilateral sobre a "ingovernabilidade das democracias", redigido por Huntington e seus colegas (Crozier, Huntington e Watanuki, 1975). Como observou Elshtain (1997, p. 27), é uma tese que legitima as desigualdades políticas: os grupos que menos participam, como as mulheres (e também trabalhadores ou integrantes de minorias raciais), seriam aqueles que estariam mais satisfeitos com a própria condição.

A interpretação lipsetiana é evidentemente inadequada para compreender o declínio da participação política nos países latino-americanos, nos quais a redemocratização veio acompanhada 
do aprofundamento da crise econômica, ou no antigo bloco comunista, onde os efeitos mais palpáveis da introdução da economia de mercado foram o sucateamento dos serviços públicos, o desemprego, o gangsterismo - numa palavra, a pauperização. Talvez seja um pouco mais plausível quando aplicada ao mundo desenvolvido. Outros indicadores, no entanto, desmentem-na.

As pesquisas de opinião pública sobre a confiabilidade das instituições, que constituem o segundo conjunto de evidências sobre a crise da representação política, devem ser lidas com cuidado. Impondo categorias e preocupações que são estranhas aos entrevistados - e também postulando uma relação entre resposta ao questionário, opinião firmada e comportamento -, elas formam um caso paradigmático daquilo que Bourdieu (1997, pp. 63-100) chama de "erro escolástico", no qual o pesquisador transfere para os outros agentes sociais a sua maneira de pensar e agir. Portanto, em vez de apresentar respostas, como crê certa ciência política, os surveys fornecem indícios, que devem ser combinados com outros para que se alcance alguma conclusão.

Além desse problema metodológico de fundo, os resultados dos surveys encontram outras dificuldades de interpretação, já que são raras as séries históricas mais longas com dados comparáveis. Ainda assim, é possível postular uma confiança baixa nas instituições representativas, mesmo nos países em que o comparecimento às eleições é elevado. De acordo com o Eurobarômetro (em pesquisa de 1996), em média 42\% dos entrevistados, nos países da União Européia, respondem que confiam nos seus parlamentos nacionais; quando a pergunta é sobre os governos nacionais, a média é de 39\%. É ainda menor a confiança nas instituições européias supranacionais. Questionados sobre o grau de influência do cidadão comum nas decisões nacionais, em média 36\% dos respondentes escolheram a opção "não muita" e 38\%, "nenhuma". Nos diferentes países da União Européia, a soma das duas categorias oscila entre 53\% (em Luxemburgo) e 84\% (no Reino Unido). ${ }^{3}$

Nos Estados Unidos, os surveys do National Opinion Research Center mostram, de 1973 a
1993, uma queda acentuada na confiança popular no poder executivo (de $29 \%$ para $12 \%$ ) e, ainda maior, no Congresso (de 24\% para 7\%). ${ }^{4}$ No caso do Brasil e dos outros países redemocratizados da América do Sul, as pesquisas adotam, muitas vezes, pressupostos bastante normativos, associando a desconfiança nas instituições representativas à adesão a valores autoritários. ${ }^{5}$ O quadro geral sustenta a mesma impressão da Europa e dos Estados Unidos: uma crise disseminada do sentimento de estar representado no governo e no legislativo, com repercussões na legitimidade das instituições.

Enfim, trata-se de um fenômeno que não está restrito a uma área geográfica ou a democracias eleitorais de tal ou qual grau de consolidação. Uma pesquisa de abrangência mundial, realizada no final da década de 1990, observou a emergência, por quase toda a parte, do que chamou de "cidadãos críticos", que combinavam elevados níveis de apoio aos princípios do regime democrático com uma confiança em declínio nas instituições políticas vigentes (Norris, 1999; em especial, Klingemann, 1999). ${ }^{6}$

O terceiro conjunto de evidências está ligado à crise dos partidos, que a partir do final do século XIX se firmaram como os principais instrumentos da representação política. O fenômeno foi estudado com detalhe nos Estados Unidos (Wattenberg, 1998), mas é perceptível também na Europa ocidental, sobretudo a partir dos anos de 1980. Num caso extremo, a Itália, ocorreu o colapso de um sistema partidário inteiro; mais ou menos por toda a parte, deu-se a dissolução das lealdades partidárias tradicionais e a personalização das escolhas dos eleitores. Há uma vasta literatura sobre essa questão. Entre os motivos para o esvaziamento dos partidos, são citados a burocratização de suas estruturas internas, o estreitamento do leque de opções políticas (com a derrota dos projetos históricos da classe operária) e, em especial, as mudanças que a mídia eletrônica introduziu na competição eleitoral.

Bernard Manin (1997, pp. 218-235) aponta a transição da democracia de partidos para uma nova democracia de audiência, caracterizada pelo contato "direto" (isto é, midiático) entre líderes e eleitores. Antes indispensáveis, as máquinas parti- 
dárias agora perderiam eficiência diante das estratégias de construção de imagem de chefes políticos que se dirigem diretamente ao público. O papel dos meios eletrônicos de comunicação na redução da influência dos partidos também é destacado por Wattenberg (1998, pp. 90-112) e Novaro (1995). Guillermo O'Donnell (1991), numa leitura mais provocativa, insinua a substituição da democracia representativa por uma nova "democracia delegativa”, caracterizada pela transferência quase irrestrita de poderes aos líderes carismáticos eleitos.

Tomados em bloco, esses três conjuntos de evidências dão peso razoável à idéia de que as democracias eleitorais vivem uma crise da representação. Justamente por isso, surgiram, nos últimos 25 anos, tantas propostas de introdução de novos mecanismos, voltados à revitalização das instituições representativas, como quotas eleitorais para grupos em desvantagem, como as mulheres, ou mesmo a substituição parcial das eleições por sorteios (ver Miguel, 2000a, 2000b). Em tais propostas, há o reconhecimento, implícito ao menos, de que a redução da confiança popular nos parlamentos e nos partidos não é efeito da "alienação", da falta de compromisso com a democracia ou de resquícios de valores autoritários? É, antes, a constatação sensata de que as instituições atualmente existentes privilegiam interesses especiais e concedem pouco espaço para a participação do cidadão comum, cuja influência na condução dos negócios públicos é quase nula. Em suma, de que as promessas da democracia representativa não são realizadas. ${ }^{8}$

Neste artigo, desejo enfocar a insuficiência da representação política, tal como entendida correntemente, apontando-a como responsável em parte pelo desencanto popular com os mecanismos representativos e sugerindo as linhas de uma interpretação mas abrangente da representação. Para tanto, valho-me do célebre debate, ocorrido nas décadas de 1960 e 1970, na ciência política de língua inglesa, sobre as "dimensões" do poder.

Buscando elevar a um patamar mais alto a disputa entre pluralistas e elitistas críticos sobre a presença ou não de uma elite dominante nos Estados Unidos, Peter Bachrach e Morton Baratz escreveram dois artigos seminais em que aponta- vam a presença de uma "face oculta" do poder político, que o debate de então tendia a ignorar. Exercer o poder não era apenas tomar decisões, mas também - talvez essencialmente - determinar a agenda política. Mais tarde, Steven Lukes acrescentaria uma terceira faceta ao poder, a capacidade de determinação autônoma de preferências. Creio que a discussão pode ser transferida, com os ajustes necessários, para o campo da representação política, que também ganha, caso seja entendida de maneira tridimensional.

Na primeira parte do artigo, faço um sumário da polêmica entre pluralistas e elitistas e da discussão sobre o conceito de poder que se seguiu a ela. Depois, apresento um resumo do conceito de representação política, para, por fim, explorar sua segunda e terceira dimensões, paralelas às dimensões do poder.

\section{O debate entre pluralistas e elitistas}

Em 1956, o sociólogo C. Wright Mills publicou aquele que seria seu livro mais influente, $A$ elite do poder (Mills, 1981 [1956]). Analisando a história política dos Estados Unidos, ele chegou à conclusão de que, por trás da fachada democrática e dos reclamos rituais de obediência à vontade popular, cristalizara-se o domínio de uma minoria, que monopolizava todas as decisões-chave. Os três pilares da "elite do poder" eram os grandes capitalistas, os principais líderes políticos e os chefes militares. Formavam uma única elite, dividida em três setores, e não três grupos concorrentes graças a mecanismos de integração, que geravam uma visão de mundo unificada e interesses compartilhados. Tais mecanismos incluíam, notadamente, o intercâmbio de posições entre os três setores (militares da reserva e políticos aposentados ingressando em conselhos de empresas; capitalistas, executivos e oficiais das três armas ocupando postos no governo) e a convivência nos ambientes das "altas rodas". Os integrantes da elites vinham das mesmas escolas e faculdades, freqüentavam as mesmas festas, clubes e restaurantes, casavam seus filhos entre si. Tudo isso reforçava a solida- 
riedade entre eles e fazia com que, cada um, ao tomar uma decisão, não deixasse de levar em conta os interesses dos outros.

A perspectiva de Wright Mills coincidia com a denúncia marxista quanto ao caráter meramente "formal" da democracia burguesa. Os direitos liberais e os mecanismos eleitorais de participação apenas esconderiam o fato de que a esmagadora maioria da população estava excluída das decisões mais importantes. Mas o sociólogo discordava dos marxistas ao apresentar a propriedade dos meios de produção como apenas uma posição de elite, em pé de igualdade com as outras. Por isso, ele vai recusar o conceito de classe social, preferindo usar uma terminologia estranha ao marxismo. ${ }^{9}$ Em vez de uma "classe dominante" - a burguesia, determinada por sua posição nas relações de produção -, há uma elite do poder, definida por critérios políticos.

Cumpre observar que a utilização do conceito de "elite", por Wright Mills, implica a subversão da teoria clássica das elites, formulada no início do século XX por autores como Vilfredo Pareto, Gaetano Mosca e Robert Michels. O objetivo que guiava as análises dos elitistas clássicos era demonstrar a impossibilidade da efetivação de um regime democrático. Assim, Pareto indicava a circulação das elites como cerne de qualquer transformação social, isto é, no fundo manifestava-se a eterna permanência da dominação sobre a massa. Mosca estabelecia que o domínio da minoria sobre a maioria consistia em regra sociológica invariável. E Michels ditava a "lei de ferro das oligarquias" para provar que a perseguição de qualquer interesse coletivo gera inevitavelmente uma elite independente. Em todos os casos, o recado era que as promessas do movimento democrático e socialista nunca seriam concretizadas.

Wright Mills vai usar o conceito de elite não para se confrontar com o ideal democrático, negando a possibilidade de sua efetivação, mas para acusar as "democracias realmente existentes" (a partir de sua realização emblemática, os Estados Unidos da América) de não cumprirem sua promessa central: o governo do povo. Dessa maneira, o caráter conformista - e, portanto, conservador - da abordagem dos elitistas clássicos é substituído por um apelo em favor do aprimoramento da democracia, com a retirada dos entraves que a preponderância das elites impunha (e impõe) a ela. Apesar de diversas inconsistências e fragilidades apontadas por seus críticos, $A$ elite do poder representou um esforço importante, da ciência social nos Estados Unidos, no sentido de uma análise mais substantiva e menos formalista dos processos políticos, que os conectasse com a estrutura da sociedade.

$\mathrm{Na}$ mesma época, um esforço com ambição semelhante alcançava conclusões opostas. Também em 1956, Robert Dahl lançou Um prefácio à teoria democrática, livro que apresenta a primeira síntese abrangente de sua teoria pluralista. ${ }^{10} \mathrm{Re}-$ servando o termo "democracia" para um ideal que raras vezes é concretizado no mundo real (e nunca em agrupamentos tão numerosos e complexos quanto Estados-nações), ele cunha a palavra "poliarquia" para designar a aproximação possível a esse ideal. Embora Dahl desenvolva um conjunto de critérios de democracia, cuja efetivação parcial definiria uma organização como poliárquica, o ponto crucial - que transparece já no significado etimológico da palavra - é a presença de uma multiplicidade de pólos de poder, sem que nenhum seja capaz de impor sua dominação a toda a sociedade. Em suma, se não podemos contar com o governo do povo ou mesmo com o governo da maioria, podemos ao menos ter um sistema político que distribua a capacidade de influência entre muitas minorias. Assim, as eleições ocupam uma posição central num ordenamento poliárquico não porque introduzam um "governo de maiorias em qualquer maneira significativa, mas [porque] aumentam imensamente o tamanho, número e variedade das minorias, cujas preferências têm que ser levadas em conta pelos líderes quando fazem opções de política" (Dahl, 1989a [1956], p. 131).

A incompatibilidade com a perspectiva de Wright Mills é muito evidente. Em lugar da ênfase no domínio de uma minoria que, embora dividida em três setores, compartilha um conjunto de valores fundamentais, Dahl apresenta uma miríade de grupos com influência localizada, entrando em coalizões sempre fluidas e provisórias para o 
exercício das funções de governo. A polêmica torna-se explícita quando, em 1958, Dahl publica o artigo "Uma crítica ao modelo de elite dirigente", com reparos metodológicos à abordagem de Wright Mills, à qual acusa, de maneira não muito velada, de se apoiar numa visão conspiratória do exercício do poder e de ser infalsificável no sentido de Popper, isto é, de não ser científica.

O artigo, então, propõe uma versão revisada do modelo, a fim de que se torne possível testá-lo. Dahl apresenta uma definição operacional de elite dirigente como sendo "uma minoria de indivíduos cujas preferências prevalecem regularmente nos casos de diferenças nas preferências sobre questões políticas chave", observando ainda que tal preponderância não pode ser um mero efeito da aplicação das regras democráticas (Dahl, 1958, p. 464). Só é possível falar na existência de uma elite do poder quando se constata a presença de uma tal minoria. Ele emprega seu teste, concluindo pela superioridade do modelo poliárquico, num estudo sobre os processos decisórios em New Haven, Connecticut, apresentada como cidade "típica" da vida urbana nos Estados Unidos. A pesquisa mostra que, embora uma minoria de líderes monopolizasse as iniciativas políticas nas três questões polêmicas analisadas (nomeações de funcionários públicos, reurbanização e educação), havia conflito dentro dela e a influência de cada líder era, via de regra, especializada, isto é, incidia sobre apenas um dos três assuntos (Dahl, 1961).

O estudo de Dahl está sujeito a uma série de questionamentos de ordem metodológica, a começar pela premissa de que o microcosmo é um retrato fiel, em escala menor, do macrocosmo quer dizer, de que o estudo dos processos de decisão em nível local pode servir de evidência para o nível nacional. Afinal, tamanho e distância são fatores essenciais para explicar a apatia política popular, que, por sua vez, é um dos elementos que favorecem o domínio da elite. Além disso, é difícil crer que uma cidade, na época com 160 mil habitantes, que sedia a Universidade Yale possa ser considerada "típica", por mais que muitos de seus indicadores demográficos sejam medianos. Mas a principal crítica foi formulada por Peter Bachrach e Morton S. Baratz em dois artigos de grande repercussão, publicados na American Political Science Review em 1962 e 1963.

Situando o debate entre elitistas e pluralistas, Bachrach e Baratz observam que sua principal fragilidade reside na redução do exercício do poder à tomada de decisões sobre questões controversas. Tentando superar essa percepção, que julgam ser demasiado simplista, eles propõem uma nova definição de poder, capaz de incorporar sua "segunda face":

É claro que o poder é exercido quando "A" participa na tomada de decisões que afetam "B". Mas o poder também é exercido quando "A" devota sua energia a criar ou a reforçar valores sociais e políticos e práticas institucionais que limitam o escopo do processo político à consideração pública apenas daquelas questões que são comparativamente inócuas para "A". Na medida em que "A" obtém sucesso a esse respeito, "B" está impedido, para todos os propósitos práticos, de trazer à baila quaisquer questões cuja resolução possa prejudicar seriamente o conjunto de preferências de "A" (Bachrach e Baratz, 1962, p. 948).

É possível chamar a segunda face do poder de "controle sobre a agenda pública". Ao ignorála, acreditando que o poder se reflete sempre em decisões concretas, Dahl não percebe que as verdadeiras "questões políticas chave", nas quais a influência da pretensa elite política deve ser testada, podem estar invisíveis. A expressão pública das divergências quanto a tais assuntos seria anulada pela certeza prévia de que nenhuma proposta alternativa teria chance de vingar. Os autores usam um exemplo institucional - as propostas que um prefeito não faz por saber de antemão que a assembléia com poder decisório seria hostil a elas (Bachrach e Baratz, 1962, pp. 951-952) mas não é difícil aplicar suas observações a esferas menos formalizadas da prática política.

Bachrach e Baratz reconhecem que o controle da agenda apresenta dificuldades de operacionalização, uma vez que se caracteriza precisamente por sua invisibilidade. Mas afirmam, com razão, que é um erro "descartar 'elementos imensuráveis' como irreais" (Bachrach e Baratz, 1962, p. 952): não é o fato de a segunda face do poder ser menos evidente e menos mensurável do que 
a primeira face (o controle sobre a decisões) que a torna menos importante para a compreensão da realidade social. Mais tarde, eles vão observar que, embora as "não-decisões" sejam, por definição, não-eventos, é possível detectar e analisar empiricamente o "processo de não-tomada de decisão" (nondecision-making process), isto é, "a mobilização do viés sobre uma questão latente" (Bachrach e Baratz, 1963, p. 641).

Dessa forma, Bachrach e Baratz apresentam uma perspectiva bidimensional do poder, acrescentando, à sua manifestação mais evidente (a tomada de decisão), uma face oculta, o impedimento da expressão do conflito político. Para Steven Lukes, que intervém no debate em 1974, com um opúsculo sobre o significado do poder, trata-se de uma visão ainda insuficiente, mesmo que represente um significativo passo adiante em relação a Dahl. Segundo o cientista político britânico, a perspectiva bidimensional mantém, tanto quanto a unidimensional, a ênfase no conflito efetivo de interesses, esteja ele aberto ou encoberto (Lukes, 1985 [1974], p. 16). Faz-se necessário acrescentar um novo elemento, a manipulação das vontades alheias. A terceira - e mais crucial - dimensão do poder residiria na capacidade de fazer com que grupos e indivíduos tivessem desejos contrários a seus verdadeiros interesses, impedindo a eclosão do conflito não apenas na arena pública, mas até mesmo na consciência dos agentes sociais (Lukes, 1985 [1974], pp. 22-23).

Fica claro que Lukes recolocou, em termos novos, a questão da ideologia. No entanto, mesmo entre os autores vinculados à tradição marxista, a tendência foi o abandono paulatino da versão mais forte da ideologia como "falsa consciência" (Eagleton, 1997 [1991]) - exatamente a que subjaz à idéia da terceira dimensão do poder. O desconforto com a noção de falsa consciência é que ela parece implicar a existência de uma consciência "verdadeira". Já que tal consciência não emerge nos sujeitos sociais, que são, afinal, as vítimas da manipulação ideológica, o passo seguinte é postular a presença de um observador privilegiado, capaz de detectar os verdadeiros interesses dos agentes, cuja veracidade não fica comprometida caso contradigam seus desejos manifestos.
Existem dois problemas principais com essa posição, que a tornam pouco sustentável. Em primeiro lugar, há a desconfiança, hoje quase universal, quanto à possibilidade de que algum observador externo seja capaz de identificar interesses melhor do que o próprio agente. A experiência do comunismo soviético mostrou os riscos políticos dessa idéia. Autonomeado porta-voz da consciência verdadeira da classe operária, o partido revolucionário sentiu-se legitimado para exercer sua ditadura sobre aqueles cujos interesses dizia representar. A não-adesão a seu programa era interpretada como conhecimento imperfeito dos próprios interesses ou, então, sintoma de desequilíbrio, a ser tratado em instituição psiquiátrica.

Convém notar que, na prática cotidiana, o preceito da inexistência do observador privilegiado é, com certa freqüência, deixado de lado. Julgamos legítimo intervir, por exemplo, para impedir um ato de automutilação ou um suicídio, da mesma forma como obrigamos as crianças a comer verduras ou ir à escola. Em tais casos, como em outros semelhantes, partimos da crença implícita de que sabemos "o que é melhor" para essas pessoas, mais do que elas mesmas sabem. A justificativa de que doentes mentais, crianças ou toxicômanos não conseguem perceber as conseqüências a médio e longo prazos de seus atos não se sustenta, já que o mesmo poder-se-ia dizer, mutatis mutandis, das vítimas da ideologia, que possuem uma visão distorcida do mundo social.

É importante frisar que a alternativa diametralmente oposta à idéia da falsa consciência - o recuo ao velho dogma utilitarista de que "cada um é o melhor juiz de seus interesses" - também não resolve o problema. Afinal, tais interesses não são dados da natureza. Eles são construídos, num processo que depende tanto dos recursos cognitivos de que dispõe o sujeito quanto de códigos sociais compartilhados. O resultado é que se impõe uma conclusão paradoxal: a possibilidade de distorção permanece, mesmo quando se abandona a crença na existência objetiva de uma consciência "correta" dos próprios interesses.

O segundo problema com a abordagem da "falsa consciência" se liga à noção, que ela também incorpora de maneira implícita ou explícita, 
de um interesse unívoco por parte dos sujeitos. Não é possível, aqui, reconstruir a polêmica entre marxistas e pós-estruturalistas, com os primeiros afirmando a preeminência dos interesses materiais, ligados à posição nas relações de produção, e os segundos observando a fragmentação das identidades em múltiplas "posições de sujeito", com interesses díspares e, por vezes, antagônicos. ${ }^{11}$ Mas, independentemente da importância relativa das diferentes identidades parciais dos indivíduos e da primazia ou não da identidade de classe, é inegável que, nas sociedades contemporâneas, os cidadãos desempenham múltiplos papéis, cujos interesses "óbvios" podem ser contraditórios. Não é difícil imaginar, por exemplo, uma contradição entre os interesses que um mesmo sujeito desenvolve na qualidade de trabalhador e na qualidade de consumidor.

Portanto, a tese central de Lukes - de que uma dimensão do exercício do poder consiste em impedir o acesso dos agentes sociais à consciência de seus reais interesses - implica uma série de premissas temerárias. Mas é possível reter seu elemento mais importante, o reconhecimento de que as vontades são produzidas socialmente e, mais ainda, que alguns agentes possuem uma capacidade superior de influência na produção das vontades de outros. Como busco fazer mais adiante, seu argumento pode ser reconstruído de uma perspectiva democrática radical, eliminando o componente autoritário em potencial que ele carrega.

\section{A representação política}

A idéia de "democracia representativa", em que o processo eleitoral ocupa um lugar central, hoje tornada lugar-comum, é bastante recente. Para o pensamento clássico - e, na verdade, até Montesquieu, Rousseau e os federalistas, no século XVIII -, democracia e eleições não se confundiam. Enquanto a democracia se apóia na premissa da igualdade fundamental entre todos os cidadãos, a eleição contempla uma seleção; implicitamente, postula a existência de indivíduos melhor preparados para ocupar os cargos públicos e, é, portanto, um mecanismo aristocrático. Em seu importante estudo sobre as origens e as transformações da democracia representativa, Bernard Manin (1997, pp. 94131) mostrou como a adoção da eleição para a indicação dos governantes, no lugar do sorteio característico da democracia grega, representou o triunfo do "princípio da distinção" aristocrático. Ellen Meiksins Wood (1995), por sua vez, apontou que as instituições representativas não surgiram como solução para a impossibilidade da democracia direta em grandes Estados; foram, desde o início, pensadas como uma forma de reduzir a presença popular no governo, reservando-o para homens com características de elite.

Desde o princípio, também, a rationale da representação foi invertida. Na prática política, os cidadãos comuns não escolhem um representante para promover seus interesses, formulação que lhes concede o papel ativo. Ao contrário, eles apenas reagem diante das ofertas que o mercado político apresenta (ver Bourdieu, 1990 [1984], 1986). O desenvolvimento dos partidos políticos, que paulatinamente passam a ocupar a posição de protagonistas, cria o fenômeno do duplo mandato, já que o representante presta contas a seu partido, tanto ou mais que a seu eleitorado.

O conceito de representação política tornase cada vez mais complexo, na medida em que a prática não se adequa aos modelos ideais correntes. A polissemia da palavra contribui para isso, pois a idéia de representação política é contaminada pelos diferentes usos de "representação" e "representar" nas artes visuais, nas artes cênicas, na literatura e no campo jurídico, entre outros. Em seu estudo fundamental sobre o tema, Hanna Pitkin chega a uma tipologia das concepções da representação política; para nossos fins, interessam duas correntes principais, que a autora chama de "representação descritiva" e "visão formalista" (Pitkin, 1967). A primeira afirma que o corpo de representantes deve formar um microcosmo da sociedade representada, reproduzindo, nas proporções adequadas, suas características principais. Nesse caso, mais importante do que aquilo que os representantes fazem é quem eles ou elas são. A visão formalista, ao contrário, enfatiza a relação entre o representante e os representados, destacando ou a au- 
torização que os cidadãos dão para que alguns ajam em seu lugar ou a prestação de contas que o representante deve fazer de seus atos, que a literatura de ciência política designa pela palavra inglesa accountability.

A predileção de Pitkin pela vertente formalista, que daria maior proteção aos cidadãos, contraposta à visão "ingênua" da representação descritiva, tem sido desafiada por teóricos mais recentes, preocupados com a reduzida presença de grupos subalternos (como mulheres, trabalhadores ou minorias étnicas) nos espaços de poder (Phillips, 1995). No entanto, há um reconhecimento mais ou menos generalizado, mesmo entre os defensores da introdução de mecanismos descritivos, de que autorização e accountability são os instrumentos cruciais da legitimação e da manutenção do vínculo entre governantes e governados.

O que importa destacar, aqui, é que as visões correntes da representação política, no senso comum, no ordenamento jurídico e também na ciência política, estão centradas no voto e na primeira dimensão, positiva, do exercício do poder: trata-se do processo de escolha de delegados para que tomem as decisões em nosso nome. A eleição ocupa uma posição de destaque absoluto já que, bifronte, é o episódio fundador e, ao mesmo tempo, a meta orientadora da relação entre representantes e representados. Ela é vista tanto como o momento da autorização para que outros decidam em nome do povo, que permanece como titular último da soberania, quanto como o momento de efetivação da accountability, quando os representados apresentam seu veredito sobre a prestação de contas dos representantes.

De maneira um tanto esquemática, é possível apontar um modelo ideal da representação política, que subjaz ao ordenamento jurídico das democracias liberais. Em primeiro lugar, na medida em que a eleição condensa a prática democrática, a formação das preferências tende a ser ignorada. Ao se dirigir à cabine de votação, o eleitor já está, ou ao menos deveria estar, de posse de uma preferência. A perspectiva liberal julga que as preferências individuais (e, por extensão, as crenças, os valores, os objetivos etc.) entram no processo político como dados, uma vez que se formam na esfera privada (Elster, 1997). O debate político e, em particular, as campanhas eleitorais permitem que o cidadão situe as diversas alternativas em relação às suas preferências e, sendo racional, como o modelo prevê, possa escolher aqueles candidatos que julgue mais adequados à consecução de seus objetivos.

Aqui já é possível perceber o peso da determinação da agenda pública no processo de escolha de representantes, mesmo dentro do modelo restrito apresentado. Para que o votante racional pondere a utilidade das diferentes alternativas eleitorais de que dispõe, ele deverá situá-las num espaço que é dado pelos vários temas controversos presentes na agenda. Ou seja, a informação é um item obviamente relevante no processo político, devendo estar disponível para a escolha esclarecida por parte dos cidadãos. Assim, a fixação da agenda condiciona as dimensões da escolha eleitoral, independentemente do grau de racionalidade e de autonomia dos eleitores na produção das próprias preferências.

É possível, agora, observar a outra face da moeda: a eleição como momento do veredicto popular, da realização da accountability. Os eleitores vão julgar o comportamento passado de seus representantes e a base para tal julgamento é o registro das posições assumidas quando estavam em questão pontos polêmicos. Mais uma vez, a decisão está condicionada - ou, ao menos, balizada - pela agenda pública estabelecida. Portanto, a relação entre representantes e representados depende, em grande medida, dos assuntos tematizados e colocados para decisão.

A introdução de uma segunda dimensão da representação política, análoga à segunda face do poder indicada por Bachrach e Baratz, implica a presença dos diferentes grupos na formação da agenda e no debate público. Mas cumpre observar que a produção da agenda política não ocorre exclusiva ou mesmo prioritariamente por ação dos representantes eleitos. Os diversos grupos de interesse presentes na sociedade disputam a inclusão ou a exclusão de temas na agenda, bem como sua hierarquização, mas quem ocupa a posição central são os meios de comunicação de massa, conforme tem demonstrado a ampla literatura sobre a cha- 
mada agenda-setting (definição de agenda). A mídia é, de longe, o principal mecanismo de difusão de conteúdos simbólicos nas sociedades contemporâneas e, uma vez que inclui o jornalismo, cumpre o papel de reunir e difundir as informações consideradas socialmente relevantes. Todos os outros ficam reduzidos à condição de consumidores de informação. Não é difícil perceber que a pauta de questões relevantes, postas para a deliberação pública, deve ser em grande parte condicionada pela visibilidade de cada questão nos meios de comunicação. Dito de outra maneira, a mídia possui a capacidade de formular as preocupações públicas. Os grupos de interesses e mesmo os representantes eleitos, na medida em que desejam introduzir determinadas questões na agenda pública, têm de sensibilizar os meios de comunicação.

Alguns teóricos da chamada "democracia deliberativa", de inspiração habermasiana, embora enfatizem o papel do debate público na organização democrática, optam por um modelo mais simples e manejável do processo político. Postulam que o parlamento é o local por excelência do debate público e que, portanto, os diferentes interesses sociais já têm porta-vozes naturais, na figura dos congressistas das várias tendências, e um espaço próprio de manifestação (ver Elster, 1998, e Stokes, 1998). Trata-se de uma percepção equivocada, pois a separação entre a esfera decisória (dos poderes instituídos) e a esfera pública discursiva é uma das características fundantes da política moderna, como o próprio Habermas, aliás, observa. É aqui que podemos incluir os meios de comunicação de massa. Nas sociedades contemporâneas, eles detêm o quase-monopólio da difusão de informações, de discursos e de representações simbólicas do mundo social; são a fonte, direta ou indireta, da esmagadora maioria das informações de que os cidadãos dispõem para compreenderem o mundo social em que vivem. Na medida em que o debate público não se limita a fóruns formais como o parlamento, mas deve alcançar o conjunto da sociedade, é evidente que a mídia passa a desempenhar uma função-chave.

É evidente também que um parlamentar pode apresentar o projeto que quiser, sobre qual- quer tema, e desta forma submeter o assunto à decisão política. Ainda assim, a influência dos meios de comunicação na formulação da agenda é significativa. Há um forte incentivo para que as intervenções e os projetos dos parlamentares sejam ligados aos temas veiculados na mídia, por dois motivos: (i) são os temas de maior visibilidade efetiva, isto é, o parlamentar que age a respeito deles mostra-se como mais atuante; e (ii) são os temas de maior visibilidade pessoal potencial, isto é, a intervenção a respeito deles tem mais chance de receber destaque na mídia. Nem sempre os parlamentares aceitam a imposição da agenda midiática e, muitas vezes, agem no sentido de modificála; a atuação de cada um vai depender do grau de vinculação a grupos de interesse definidos e da posição no campo político (Miguel, 2002). Mas não se pode ignorar o incentivo presente para políticos em busca de reeleição, nem o fato de que a tramitação congressual de questões de pequena visibilidade tende a ser simbólica ou muito lerda, quando não abortada.

Participar da elaboração da agenda e participar do debate público são, como já deve estar claro, quase sinônimos: o debate gira, em grande parte, em torno da composição e da hierarquização da agenda, com os diferentes grupos procurando destacar - ou, ao contrário, deixar na obscuridade - certos temas ou problemas. Entretanto, não basta apresentar os problemas; é necessário "enquadrá-los", isto é, construir uma narrativa que permita identificar sua gênese, seus elementos, seus desdobramentos, as possíveis soluções. ${ }^{12}$ A decisão depende, em grande medida, do enquadramento dominante. Nem sempre a capacidade de incluir o tema na agenda leva à possibilidade de disputar a imposição de um enquadramento. Formas de ação direta, com recurso à violência ou à desobediência civil, por exemplo, podem ser eficazes para despertar a atenção para um problema, mas os grupos que recorrem a ela perdem legitimidade para serem aceitos como interlocutores públicos, sendo substituídos por outros, mais moderados (Gamson e Meyer, 1996, pp. 287-289). Na difusão dos diferentes enquadramentos, mais uma vez, os meios de comunicação de massa ocupam um papel central. 
Sintetizando o argumento desenvolvido até o momento, a função de representação política significa participar de processos de tomada de decisão em nome de outros (primeira dimensão), mas também participar da confecção da agenda pública e do debate público em nome de outros. Essa segunda dimensão é necessária porque, em sociedades populosas, extensas e complexas como as contemporâneas, a participação direta de todos no debate público é inviável. Da mesma maneira como a impossibilidade de tomada direta de decisões pelo povo torna imprescindivel a representação parlamentar, a impossibilidade de uma discussão envolvendo a todos gera a necessidade da representação das diferentes vozes da sociedade no debate público. ${ }^{13}$

Fica claro que os meios de comunicação de massa exercem uma função representativa nas sociedades contemporâneas. Em especial através do jornalismo, mas não só, a mídia nos diz diariamente o que é o mundo e, embora possamos recorrer a outras fontes, elas sempre permanecem em posição secundária, de complementaridade (Miguel, 1999). Neste "dizer o que é o mundo" está incluído o recorte dos fatos relevantes, das interpretações desses fatos, das alternativas que estão postas.

Entender os meios de comunicação como uma esfera de representação política é entendêlos como espaço privilegiado de disseminação das diferentes perspectivas e projetos dos grupos em conflito na sociedade. Isso significa que o bom funcionamento das instituições representativas exige que sejam apresentadas as vozes dos vários agrupamentos políticos, permitindo que o cidadão, em sua condição de consumidor de informação, tenha acesso a valores, argumentos e fatos que instruem as correntes políticas em competição e possa formar, de modo abalizado, sua própria opinião política. É o que se pode chamar de "pluralismo político" da mídia. Mas significa também, sobretudo em sociedades estratificadas e multiculturais, permitir a disseminação das visões de mundo associadas às diferentes posições no espaço social, que são a matéria-prima na construção das identidades coletivas - que, por sua vez, fundam as opções políticas. É o que vou chamar de "pluralismo social".
É evidente que a representação nos fóruns decisórios estabelecidos, caracterizada pela delegação de poder na forma do mandato eletivo, e a representação no debate público e na formação da agenda, que ocorre em grande medida por intermédio da mídia, ganham aspectos diferentes. $\mathrm{Na}$ primeira, a relação entre representantes e representados assume uma feição muito mais formalizada (e, por isso mesmo, muito mais explícita); mas é também uma relação descontínua, que se cristaliza no momento das eleições. Dificilmente poder-se-ia pensar em algo tão institucionalizado para a agenda e o debate, na medida que, entre suas características, estão a fluidez e multiplicidade de espaços em que acontecem - e é bom que seja assim, uma vez que isso indica a possibilidade permanente de re-apropriação pela sociedade dos assuntos públicos. Ainda assim, é importante assinalar a necessidade de que os meios de comunicação representem de maneira adequada as diferentes posições presentes na sociedade, incorporando tanto o pluralismo político quanto o social.

Hoje, via de regra, a mídia desempenha mal esta tarefa, por diversas razões, que incluem os interesses dos proprietários das empresas de comunicação, a influência dos grandes anunciantes, a posição social comum dos profissionais do setor e a pressão uniformizadora da disputa pelo público. Mais até do que a manipulação consciente - que, no entanto, é uma possibilidade sempre presente, sobretudo em momentos cruciais -, há a adesão inconsciente a determinada percepção do mundo, que preside a seleção e a hierarquização de temas, enfoques e valores. ${ }^{14} \mathrm{O}$ resultado é a apresentação de uma imagem enviesada da sociedade.

O aprimoramento da representatividade social da mídia, que é o conteúdo da bandeira da "democratização da comunicação", não possui solução mágica. A distinção, inelutável, entre produtores e consumidores de informação gera por si só uma série de desafios para a prática democrática, exatamente da mesma maneira como, em relação à primeira dimensão da representação política, a separação funcional entre cidadãos comuns e tomadores de decisão coloca, de chofre, proble- 
mas inexistentes nas democracias diretas da Antigüidade. A solução é sempre provisória e aproximada. Não consiste numa única providência; pelo contrário, engloba um conjunto de medidas, que começa na desconcentração da propriedade de empresas de comunicação - o que permanece dentro da lógica da concorrência mercantil e da utopia liberal do "livre mercado de idéias" - e chega na qualificação do público, dotando-o de um senso crítico mais apurado para a leitura das informações que consome. ${ }^{15}$

O ponto mais importante é dissociar capacidade de prover informações - isto é, do usufruto da liberdade de expressão enquanto liberdade positiva - da posse do poder econômico, através de instrumentos como o direito de antena (que reserva tempo na mídia comercial para que movimentos sociais e organizações da sociedade civil veiculem suas posições), o incentivo ao jornalismo, rádio e televisão comunitários e o financiamento público para estimular a expressão de grupos desprivilegiados. ${ }^{16}$ São medidas voltadas à equalização do acesso às formas de expressão pública entre os diversos grupos sociais, que devem ter condições de participar do debate com sua própria voz.

Cumpre observar que a desigualdade de acesso à discussão pública não é efeito apenas do controle da mídia, mas também da deslegitimação da expressão dos dominados no campo político, que exige o manejo de determinados modos de discurso. Como observou Pierre Bourdieu, "a linguagem dominante [no campo político] destrói, ao desacreditá-lo, o discurso político espontâneo dos dominados: não lhes deixa outra opção que não o silêncio ou a linguagem emprestada, cuja lógica não é mais a do uso popular, sem ser a do uso culto, linguagem enguiçada, onde as 'palavras elevadas' estão presentes apenas para assinalar a dignidade da intenção expressiva e que, nada podendo transmitir de verdadeiro, de real, de 'sentido', priva aquele que a fala da experiência mesma que julga exprimir" (Bourdieu, 1979, p. 538). Em tais circunstâncias, a um grupo dominado resta apenas a opção de calar ou ser falado, isto é, de esperar que seus presumíveis interesses sejam abrigados no discurso de outros.
Nesse ponto, já estamos avançando para uma terceira dimensão da representação política, ligado ao que Lukes chama de controle sobre as preferências. Do ângulo que interessa no momento, isso implica dizer que uma boa representação política é a representação de preferências formuladas autonomamente. "Formuladas" é a palavrachave: estou incorporando aqui a idéia de que os interesses não são dados fixos, não são naturais, nem são o reflexo automático de determinadas condições materiais. É necessário que os agentes coletivos possam produzir suas próprias preferências, a partir do entendimento compartilhado sobre sua situação no mundo, num processo dialógico. Portanto, fica afastado o matiz autoritário, presente na formulação da terceira dimensão do poder por Steven Lukes.

Ao mesmo tempo, há um deslocamento importante em relação a certas noções influentes sobre o funcionamento da democracia. Apontar a necessidade de espaços autônomos de produção das preferências significa que não basta a existência de uma "esfera pública" em que diferentes posições entram em debate, conforme a formulação canônica de Habermas. Se isso ocorre, os grupos sociais que têm menor capacidade de constituição autônoma de seus próprios interesses - os grupos dominados, possuidores de menor capital, tanto econômico como cultural - estarão em posição desvantajosa. Na verdade, estarão quase que fadados a abraçar "preferências adaptativas", isto é, a escolher apenas uma das alternativas em foco, sem a possibilidade de gerar novas opções (Sustein, 1991, pp. 19-24; Knight e Johnson, 1997, p. 298). O modelo de uma esfera pública única, cujos participantes são vistos como indivíduos livres do pertencimento a grupos, presente no ideal da democracia deliberativa, apenas reproduz, num patamar diferente, os problemas das instituições políticas liberais, que privilegiam os interesses mais imediatos das classes dominantes, como mostraram Claus Offe e Helmut Wiesenthal (1984 [1980]).

Portanto, é necessário que haja uma quantidade de esferas públicas concorrentes, isto é, de espaços em que os grupos da sociedade possam criar os interesses que, depois, serão representa- 
dos nos fóruns políticos gerais, inclusive no parlamento. Nancy Fraser propõe a expressão "contrapúblicos subalternos, para assinalar que são arenas discursivas paralelas, onde membros de grupos sociais subordinados inventam e difundem contradiscursos para formular interpretações opositivas de suas identidades, interesses e necessidades" (Fraser, 1992, p. 123). ${ }^{17}$ O principal exemplo que ela fornece é o do movimento feminista nos Estados Unidos, a partir do início do século XX, que construiu uma visão dos interesses das mulheres - e mesmo um conjunto de novos conceitos, como "dupla jornada", "assédio sexual" e outros - que depois transportou, com relativo êxito, para a esfera pública ampla.

Apesar da polêmica posterior entre as duas autoras, sobre o caráter econômico e cultural das desigualdades sociais, a posição de Fraser é congruente com a apresentada por Iris Marion Young (1990, pp. 184-91). Esta última propunha o financiamento público para incentivar a auto-organização dos grupos oprimidos, canais especiais de acesso aos fóruns decisórios e mesmo poder de veto sobre políticas públicas que os atingissem em particular, proposição da qual recua em sua obra mais recente (Young, 2000, pp. 149-150). O ponto importante é o primeiro, a busca da autoorganização, que permite que os grupos sociais construam de maneira autônoma sua própria identidade.

Assim, a terceira dimensão aqui apresentada desloca, de forma ainda mais decisiva do que a segunda, a representação política para o campo da sociedade civil - e do exercício ativo da cidadania, entendida segundo a "concepção alternativa” apontada por Alvarez, Dagnino e Escobar, que destaca a "ampla gama de esferas públicas possiveis onde a cidadania pode ser exercida e os interesses da sociedade não somente representados, mas também fundamentalmente re/modelados" (Alvarez, Dagnino e Escobar, 2000 [1998], p. 16). Não há possibilidade de uma representação política mais adequada sem a presença de uma sociedade civil desenvolvida e plural, na medida em que tal sociedade civil é a própria base da prática dessa cidadania e dos contrapúblicos mencionados por Fraser.

\section{Conclusão}

A teoria ampliada da representação política, aqui esboçada, orienta-se na direção de dois valores principais. Em primeiro lugar, a busca do aprofundamento do pluralismo político, dando vez não apenas à expressão dos grupos de interesse constituídos, como no pluralismo liberal padrão, mas também à plena constituição dos interesses dos grupos. Ao contrário de muitas correntes críticas das democracias liberais contemporâneas - aí incluída boa parte dos deliberacionistas de matiz habermasiano, participacionistas, republicanistas cívicos e, sobretudo, comunitaristas -, não se vislumbra alguma forma de democracia unitária em que as diferenças sociais sejam abolidas e o consenso sobre o "bem comum" fique ao alcance da mão - ou da imaginação. O caminho é antes o inverso, contemplando a expressão e a representação de todos.

Em segundo lugar, o reconhecimento do valor da autonomia, no sentido de produção das regras sociais por aqueles que estarão submetidos a elas. É algo que exige não apenas a liberdade de escolha, mas também "decisões alcançadas com uma consciência completa e vívida das oportunidades disponíveis, com referência a toda a informação relevante e sem constrangimentos ilegítimos ou excessivos no processo de formação de preferências" (Sustein, 1991, p. 11). O principal rebaixamento que o liberalismo provocou no ideal democrático foi o descarte da autonomia como algo utópico, inalcançável, quando não potencialmente perigoso (já que pode conduzir à "tirania da maioria"). A democracia reduziu-se, então, à forma política que garantiria o usufruto das liberdades na esfera privada - a versão "protetora" do ordenamento democrático, na tipologia de Macpherson (1978 [1977]) - e a circulação das elites.

Dentro dessa moldura, a representação política como tal tem pouco significado, com instituições, como, por exemplo, o parlamento, que servem, sobretudo, de espaço de treinamento para líderes políticos, algo que os escritos fundadores de Weber (1993 [1918]) e Schumpeter (1984 [1942]) já colocavam com clareza (e, na verdade, com mais clareza do que seus sucessores). O es- 
forço de aprimoramento dos mecanismos representativos só ganha sentido se conectado a um ideal mais substantivo da democracia.

Entretanto, tal aprimoramento transborda o espaço das instituições políticas formais. Conforme procurei demonstrar, a crise da representação não se resolve nas esferas representativas em sentido estrito. Muitas vezes, o problema é abordado dessa forma limitada e as soluções propostas passam por reforma no sistema eleitoral, com a introdução do voto majoritário ou da representação proporcional, conforme o caso; pela introdução de mecanismos inovadores para a seleção de representantes, como quotas para grupos politicamente dominados; pela geração de fóruns de cidadãos escolhidos de maneira aleatória ("representativos" no sentido descritivo), que interagiriam com as instituições tradicionais e garantiriam sua maior proximidade com as pessoas comuns. São idéias interessantes, dignas de discussão e, algumas delas, até mesmo necessárias para o aperfeiçoamento da representação política. Mas são insuficientes.

Medidas cruciais passam por espaços externos à representação nos fóruns de tomada de decisão. Explorei duas "dimensões" adicionais, englobando o acesso ao debate público (e, portanto, aos meios de comunicação) e a auto-organização na sociedade civil, justificando as vantagens de um entendimento ampliado do conceito. Há mais um elemento que deve ser mencionado. Não se trata de uma nova dimensão da representação, mas, antes, de uma precondição do funcionamento de um regime democrático: a difusão das condições materiais mínimas que propiciem, àqueles que o desejem, a possibilidade de participação na política.

Anne Phillips, uma autora que se mostra preocupada com a ausência da questão da igualdade material no debate atual sobre a democracia, observa que não há uma relação de mão única entre política e economia. O "empoderamento" dos grupos sociais marginalizados - ou seja, seu acesso às esferas de poder, com a capacidade de pressão daí derivada - é, por vezes, um pré-requisito para a transformação estrutural (Phillips, 1999, p. 31). Isso serve de lembrete contra a simplificação levada a cabo pelo marxismo vulgar, que desdenhava as liberdades civis e políticas como meramente "formais" e acreditava numa determinação mecânica da "superestrutura" pela "base". No entanto, é importante apontar que a esfera política não está desconectada do restante da sociedade e que, sem um mínimo de igualdade material e garantia das condições básicas de existência, o funcionamento da democracia está gravemente comprometido.

\section{NOTAS}

1 A fonte mais acessível de dados sobre comparecimento eleitoral em todo o mundo é o relatório "Voter turnout from 1945 to date: a global report on political participation", do Institute for Democracy and Electoral Assistance (IDEA), disponível no site www.idea.int. Como os dados mais recentes estão incompletos, para as eleições de 2000 nos Estados Unidos foi usado o David Leip's Atlas of U.S. Presidential Elections (no site uselectionatalas.org). Todas as análises aqui feitas tomam por base eleições gerais para a Presidência da República ou, no caso de regimes parlamentaristas, para o parlamento nacional.

2 Na Bélgica e na Austrália, o voto é obrigatório.

3 As tabelas estão em http://europa.eu.int/comm/ dg10/epo/eb/eb45/tables9/chapter7.pdf.

4 Esses dados e outros, similares, são resumidos em Cappella e Jamieson (1997, pp. 17-19).

5 É o caso, entre outros, de Moisés (1995) e de Linz e Stepan (1999 [1996]); e também dos surveys do Latinobarómetro (Lagos, 2001; e no site http://www. latinobarometro.org).

6 O conjunto de pesquisas presente no livro editado por Norris possui problemas metodológicos consideráveis, a começar pela tendência a uma adesão pouco crítica aos resultados dos surveys e por operacionalizações um tanto arbitrárias dos conceitos, como a medição do nível de apoio à comunidade política por meio de respostas a questões sobre o "orgulho nacional" e a disposição para lutar numa guerra (Klingemann, 1999, p. 40). Também é discutível a tradução da insatisfação dos cidadãos com as instituições representativas em termos de um descompasso entre percepções "idealistas" e "realistas" da democracia (ver Norris, 1999, p. 11). Mas, tomados os devidos cuidados, o painel apresentado da percepção popular das democracias eleitorais é bastante significativo. 
7 Dahl (2000) cunhou a expressão "paradoxo democrático" para indicar a situação de descontentamento com o desempenho das instituições democráticas concomitante a uma firme adesão aos princípios da democracia.

8 O imbroglio envolvendo as eleições presidenciais de 2000 nos Estados Unidos revelou com clareza que, mais do que expressar uma vontade popular, o processo eleitoral cumpre o papel de um ritual de relegitimação do sistema político: não era importante contar de fato os votos, e sim proclamar um vitorioso com respaldo institucional.

9 Embora a obra de Wright Mills tenha inspirado uma das mais influentes tentativas de interpretação marxista do Estado contemporâneo (Miliband, 1972 [1969]).

10 Uma segunda síntese aparece no livro Poliarquia, de 1971. Nele, Dahl apresenta um modelo muito mais enxuto, elegante e operacionalizável do que o de quinze anos antes (e por isso exerce uma enorme influência na ciência política posterior), mas, a meu ver, ao preço de uma estilização excessiva, que reduz seu poder de interpretação da realidade (Dahl, 1971). Daí para diante, numa trajetória intelectual invulgar, Dahl se mostra cada vez mais crítico em relação ao sistema político dos Estados Unidos, denunciando os constrangimentos que a ordem capitalista impõe à democratização (ver, em especial, Dahl, 1990 [1985], e 1989b).

11 A posição pós-estruturalista é desenvolvida em Laclau (1986) e, sobretudo, Laclau e Mouffe (1987 [1985]). Para uma resposta marxista ortodoxa, ver Wood (1998 [1989]).

12 A noção de "enquadramento" (framing), central nos estudos contemporâneos sobre a relação entre mídia e política, deriva da obra de Goffman (1986 [1974]).

13 Keane (1991, p. 43) anota este ponto, em meio a uma crítica à concepção liberal de liberdade de imprensa, mas não chega a desenvolvê-lo.

14 Há uma vasta literatura sobre esses pontos. Ver, entre muitos outros, Entman (1989), Page (1996), Bourdieu (1996), Fallows (1997 [1996]), Bagdikian (1997), McChesney (1999) e Ramonet (1999).

15 É o movimento chamado, nos países de língua inglesa, de "media literacy" (ver Lewis e Jhally, 1998).

16 "Pacotes" de propostas para a democratização da comunicação aparecem em Entman, (1989, pp. 134139), Keane (1991, pp. 163-193), Chester e Wright (1996), McChesney (1999, pp. 301-316) e Leys (1999, pp. 328-330). Algumas das medidas mencionadas aqui têm sido incorporadas em diferentes le- gislações nacionais; para uma pesquisa comparativa entre 13 países da Europa e das Américas, ver Querino (2002).

17 Em sentido similar, Mansbridge (1996, p. 58) fala em "enclaves de discurso opositor".

\section{BIBLIOGRAFIA}

ALMOND, Gabriel A. \& VERBA, Sidney. (1963), The civic culture: political attitudes and democracy in five nations. Princeton, Princeton University Press.

ALVAREZ, Sonia E.; DAGNINO, Evelina \& ESCOBAR, Arturo. (2000 [1998]), "Introdução: o cultural e o político nos movimentos sociais latino-americanos", in Sonia E. Alvarez, Evelina Dagnino e Arturo Escobar (orgs.), Cultura e politica nos movimentos sociais latino-americanos: novas leituras, Belo Horizonte, Editora da UFMG.

BACHRACH, Peter \& BARATZ, Morton S. (1962), "Two faces of power". American Political Science Review, 56 (4): 947-952.

(1963), "Decisions and nondecisions: an analytical framework". American POlitical Science Review, 57 (3): 632-642.

BAGDIKIAN, Ben. (1997), The media monopoly. Boston, Beacon Press.

BOURDIEU, Pierre. (1979), La distinction. Paris, Minuit.

(1986), "La représentation politique: eléments pour une théorie du champ politique". Actes de la Recherche en Sciences Sociales, 64: 5-19

(1990 [1984]), "A delegação e o fetichismo político", in Coisas ditas, São Paulo, Brasiliense.

(1996), Sur la télévision, suivi de l'emprise du journalisme. Paris, Liber. 
. (1997), Méditations pascaliennes. Paris, Seuil.

CAPPELLA, Joseph N. \& JAMIESON, Kathleen Hall. (1997), Spiral of cynicism: the press and the public good. Oxford, Oxford University Press.

CHESTER, Jeffrey A. \& WRIGHT, Anthony. (1996), "A twelve-step program for media democracy". The Nation, 262 (22): 21.

CROZIER, Michel J.; HUNTINGTON, Samuel P. \& WATANUKI, Joji. (1975), The crisis of democracy: report on the governability of democracies to the Trilateral Comission. Nova York, New York University Press.

DAHL, Robert A. (1958), "A critique of the ruling elite model". American Political Science Review, 52 (2): 463-469.

(1961), Who governs? Democracy and power in an American city. New Haven, Yale University Press.

(1971), Polyarchy: participation and opposition. New Haven, Yale University Press.

(1989a [1956]), Um prefácio à teoria democrática. Rio de Janeiro, Jorge Zahar.

(1989b), Democracy and its critics. New Haven, Yale University Press.

(1990 [1985]), Um prefácio à democracia econômica. Rio de Janeiro, Jorge Zahar.

(2000), "A democratic paradox?" Political Science Quaterly, 115 (1): 35-40.

EAGLETON, Terry. (1997 [1991]), Ideologia: uma introdução. São Paulo, Editora da Unesp/Boitempo.

ELSHTAIN, Jean Bethke. (1997), Real politics: at the center of everyday life. Baltimore, The Johns Hopkins University Press.
ELSTER, Jon. (1997), "The market and the forum: three varieties of political theory", in James Bohman e William Rehg (eds.), Deliberative democracy: essays on reason and politics, Cambridge (Mass.), The MIT Press.

(1998), "Deliberation and constitution making”, in Jon Elster (ed.), Deliberative democracy, Cambridge, Cambridge University Press.

ENTMAN, Robert M. (1989), Democracy without citizens: media and the decay of American politics. Oxford, Oxford University Press.

FALLOWS, James. (1997 [1996]), Detonando a notícia: como a mídia corrói a democracia americana. Rio de Janeiro, Civilização Brasileira.

FRASER, Nancy. (1992), "Rethinking the public sphere: a contribution to the critique of actually existing democracy", in Craig Calhoun (ed.), Habermas and the public sphere, Cambridge (Mass.), The MIT Press.

GAMSON, William A. \& MEYER, David S. (1996), "Framing political opportunity", in Doug McAdam; John D. McCarthy e Mayer N. Zald (eds.), Comparative perspectives on social movements: political opportunities, mobilizing structures, and cultural framings, Cambridge, Cambridge University Press.

GOFFMAN, Erving. (1986 [1974]), Frame analysis: an essay on the organization of experience. Reedição. Boston, Northeastern University Press.

KEANE, John. (1991), The media and democracy. Cambridge, Polity.

KLINGEMANN, Hans-Dieter. (1999), "Mapping political support in the 1990s: a global analysis", in Pipa Norris (ed.), Critical citizens: global support for democratic governance, Oxford, Oxford University Press. 
KNIGHT, Jack \& JOHNSON, James. (1997), "What sort of political equality does deliberative democracy require?", in James Bohman e William Rehg (orgs.), Deliberative democracy: essays on reason and politics, Cambridge (Mass.), The MIT Press.

LACLAU, Ernesto (1986), "Os novos movimentos sociais e a pluralidade do social". Revista Brasileira de Ciências Sociais, 2: 41-47.

LACLAU, Ernesto \& MOUFFE, Chantal. (1987 [1985]), Hegemonia y estrategia socialista: hacia una radicalización de la democracia. Madrid, Siglo Veintiuno.

LAGOS, Marta. (2001), "Between stability and crisis in Latin America". Journal of Democracy, 12 (1): 137-145.

LEWIS, Justin \& JHALLY, Sut. (1998), "The struggle over media literacy". Journal of Communication, 48 (1): 109-120.

LEYS, Colin. (1999), "The public sphere and the media: market supremacy versus democracy", in Leo Panitch e Colin Leys (eds.), Global capitalism versus democracy, Suffolk, Merlin Press.

LINZ, Juan J. \& STEPAN, Alfred. (1999 [1996]), $A$ transição e consolidação da democracia: a experiência do Sul da Europa e da América do Sul. São Paulo, Paz e Terra.

LIPSET, Seymour Martin. (1963 [1960]), Political man: the social bases of politics. Reedição. Garden City, Anchor Books.

LUKES, Steven. (1985 [1974]), El poder: un enfoque radical. Madrid, Siglo Veintiuno.

MACPHERSON, C. B. (1978 [1977]), A democracia liberal: origens e evolução. Rio de Janeiro, Zahar.

MANIN, Bernard. (1997), The principles of representative government. Cambridge, Cambridge University Press.
MANSBRIDGE, Jane. (1996), "Using power/fighting power: the polity", in Seyla Benhabib (ed.), Democracy and difference: contesting the boundaries of the political, Princeton, Princeton University Press.

McCHESNEY, Robert W. (1999), Rich media, poor democracy: communication politics in dubious times. Urbana, University of Illinois Press.

MIGUEL, Luis Felipe. (1999), "O jornalismo como 'sistema perito'”. Tempo Social, 11 (1): 197-208.

. (2002), "Os meios de comunicação e a prática política”. Lua Nova, 55-6: 155-84.

. (2000a), "Sorteios e representação democrática". Lua Nova, 50: 69-96

(2000b), "Teoria política feminista e liberalismo: o caso das cotas de representação". Revista Brasileira de Ciências Sociais, 44: 91-102.

MILIBAND, Ralph. (1972 [1969]), O Estado na sociedade capitalista. Rio de Janeiro, Zahar.

MILLS, C. Wright. (1981 [1956]), A elite do poder. Rio de Janeiro, Zahar.

MOISÉS, José Álvaro. (1995), Os brasileiros e a democracia: bases sócio-políticas da legitimidade democrática. São Paulo, Ática.

NORRIS, Pippa (ed.). (1999), Critical citizens: global support for democratic governance. Oxford, Oxford University Press.

NOVARO, Marcos. (1995), "O debate contemporâneo sobre a representação política”. Novos Estudos Cebrap, 42: 77-90.

O'DONNELL, Guillermo. (1991), "Democracia delegativa?" Novos Estudos Cebrap, 31: 25-40.

OFFE, Claus \& WIESENTHAL, Helmut. (1984 [1980]), "Duas lógicas da ação coletiva: anotações teóricas sobre classe social e forma organizacional", in Claus Offew, 
Problemas estruturais do Estado capitalista, Rio de Janeiro, Tempo Brasileiro.

PAGE, Benjamin I. (1996), Who deliberates? Mass media in modern democracy. Chicago, The University of Chicago Press.

PHILLIPS, Anne. (1995), The politics of presence. Oxford, Oxford University Press. (1999), Which equalities matter? Cambridge, Polity.

PITKIN, Hanna Fenichel. (1967), The concept of representation. Berkeley, University of California Press.

QUERINO, Ana Carolina. (2002), "Legislação de radiodifusão e democracia: uma perspectiva comparada". Comunicação€́política, nova série, IX(2): 152-189.

RAMONET, Ignacio. (1999), La tyrannie de la communication. Paris, Galilée.

RAMOS, Paola Novaes. (2001), Alheamento decisório eleitoral: o significado de votos em branco, votos nulos e abstenções eleitorais para democracias representativas contemporâneas. Monografia, Brasília, Departamento de Ciência Política da UnB.

SCHUMPETER, Joseph. (1984 [1942]), Capitalismo, socialismo e democracia. Rio de Janeiro, Zahar.

STOKES, Susan C. (1998), "Pathologies of deliberation", in Jon Elster (ed.), Deliberative democracy, Cambridge, Cambridge University Press.

SUSTEIN, Cass R. (1991), "Preferences and politics". Philosophy and Public Affairs, 20 (1): 3-34.

WATTENBERG, Martin P. (1998), The decline of American political parties, 1952-1996. Cambridge (Mass.), Harvard University Press.

WEBER, Max. (1993 [1918]), Parlamento e governo na Alemanha reordenada: crítica po- lítica do funcionalismo e da natureza dos partidos. Petrópolis, Vozes.

WOOD, Ellen Meikisins. (1995), "The demos versus 'we, the people': from ancient to modern conceptions of citizenship", in , Democracy against capitalism: rebewing historical materialism, Cambridge, Cambridge University Press.

. (1998 [1989]), The retreat from class: $a$ new "true" socialism. Reedição. Londres, Verso.

YOUNG, Iris Marion. (1990), Justice and the politics of difference. Princeton, Princeton University Press.

. (2000), Inclusion and democracy. Oxford, Oxford University Press. 


\section{REPRESENTAÇÃO POLÍTICA EM 3-D: ELEMENTOS PARA UMA TEORIA AMPLIADA DA REPRESENTAÇÃO POLÍTICA}

\author{
Luis Felipe Miguel
}

\section{Palavras-chave}

Representação política; Democracia; Agenda pública; Mídia; Sociedade civil.

O artigo discute os impasses e as alternativas para a representação política, tomando como ponto de partida a polêmica sobre o conceito de poder, travada nos anos de 1960 e 1970 na ciência política anglo-saxã e envolvendo, notadamente, Robert Dahl, Bachrach, Baratz e Steven Lukes. De acordo com o último, a compreensão do poder deve levar em conta três dimensões: 1) a capacidade de tomar decisões ou de vetá-las; 2) o controle sobre a agenda, isto é, a determinação das questões que serão alvo de decisão; e 3) a capacidade de anular o conflito social, impedindo que indivíduos e grupos sociais tomem consciência de seus verdadeiros interesses. Apesar dos problemas presentes nessa formulação, ela é útil para pensar a representação política. As teorias predominantes levam em consideração apenas a face mais evidente da representação política, a escolha daqueles que tomarão as decisões. Mas uma democracia representativa mais próxima do ideal de soberania popular deveria contemplar a segunda dimensão - a formação da agenda, hoje fortemente determinada pelos meios de comunicação de massa. Portanto, cabe entender a mídia como sendo também um espaço de representação política. E o reconhecimento da terceira dimensão implica a necessidade de geração de espaços que permitam aos grupos subalternos formularem autonomamente seus interesses, isto é, de uma sociedade civil desenvolvida e plural.

\section{3-D POLITICAL REPRESENTA- TION: ELEMENTS FOR AN AMPLIFIED THEORY OF PO- LITICAL REPRESENTATION}

Luis Felipe Miguel

\section{Keywords}

Political representation; Democracy, Public agenda; Mass media; Civil society.

The article discusses the impasses and alternatives to political representation, taking as starting point the controversy about the concept of power, which occurred in the sixties and seventies in the Anglo-Saxon political science and involved, notably, Robert Dahl, Bachrach \& Baratz, and Steven Lukes. According to Lukes, the understanding of power must consider three dimensions: (1) the aptness to take decisions or to veto them; (2) the control over the agenda, that is, the determination of the questions that will be object of decisions; and (3) the aptness to nullify social conflict, by preventing individuals and social groups from taking consciousness of their true interests. Despite its problems, this formula is useful to think political representation. Predominant theories take only the most evident face of political representation into account: the choice of decisionmakers. But a representative democracy closer to the ideal of popular sovereignty would have to include a second dimension - the formation of agenda, what is strongly influenced by mass media. Hence, it is necessary to understand mass media as also a sphere of political representation. And recognition of the third dimension implies the need of generating spaces where subaltern groups can autonomously formulate their interests, that is, a developed and plural civil society.

\section{REPRÉSENTATION POLITIQUE EN 3-D: ÉLÉMENTS POUR UNE THÉORIE ÉLARGIE DE LA RE- PRÉSENTATION POLITIQUE}

\author{
Luis Felipe Miguel
}

\author{
Mots-clés \\ Représentation politique; Démocra- \\ tie; Agenda public; Médias; Société \\ civile.
}

Cet article discute les impasses et les alternatives pour la représentation politique, en prenant comme point de départ la polémique sur le concept de pouvoir, qui a eu lieu dans la science politique anglo-saxonne au cours des années 1960 et 1970, avec la participation, entre autres, de Robert Dahl, Bachrach, Baratz et Steven Lukes. D'après ce dernier, la compréhension du pouvoir doit considérer trois dimensions: (1) la capacité de prendre décisions ou de les interdire; (2) le contrôle sur l'agenda, c'est-à-dire, la détermination des questions qui seront objet de décision; et (3) la capacité d'annuler le conflit social, en empêchant des individus et des groupes sociaux de prendre conscience de leurs véritables intérêts. Malgré ces problèmes, cette formule est utile pour penser la représentation politique. Les théories prédominantes considèrent uniquement le côté le plus évident de la représentation politique, le choix de ceux qui vont prendre les décisions. Mais une démocratie représentative plus proche de l'idéal de souveraineté populaire devrait contempler la seconde dimension, la formation de l'agenda, qui souffre, de nos jours, de l'intense influence des médias. Il faut donc reconnaitre les médias comme un espace de représentation politique. La reconnaissance de la troisième dimension implique dans le besoin de génération des espaces pour que les groupes subalternes formulent avec autonomie leurs intérêts, c'est-à-dire, ceux d'une société civile développée et plurielle. 